Article

\title{
Investigating Carnivore Guild Structure: Spatial and Temporal Relationships amongst Threatened Felids in Myanmar
}

\author{
Pyae Phyoe Kyaw ${ }^{1,2}, * \mathbb{D}$, David W. Macdonald ${ }^{1}$, Ugyen Penjor ${ }^{1,3}{ }^{(}$, Saw Htun ${ }^{2}$, Hla Naing ${ }^{2}$, Dawn Burnham ${ }^{1}$, \\ Żaneta Kaszta ${ }^{1}$ and Samuel A. Cushman ${ }^{4}$ \\ 1 Wildlife Conservation Research Unit, Department of Zoology, The Recanti-Kaplan Centre, University of \\ Oxford, Tubney House, Tubney OX13 5QL, UK; david.macdonald@zoo.ox.ac.uk (D.W.M.); \\ ugyen.penjor@zoo.ox.ac.uk (U.P.); dawn.burnham@zoo.ox.ac.uk (D.B.); zaneta.kaszta@zoo.ox.ac.uk (Ż.K.) \\ 2 Wildlife Conservation Society Myanmar Program, Yangon 11041, Myanmar; shtun@wcs.org (S.H.); \\ hlanaipanthera@gmail.com (H.N.) \\ 3 Nature Conservation Division, Department of Forests and Park Services, Taba, Thimphu 11001, Bhutan \\ 4 US Forest Service, Rocky Mountain Research Station, Flagstaff, AZ 86001, USA; samuel.cushman@usda.gov \\ * Correspondence: pkyaw@wcs.org or pyaephyoekyawwcs@gmail.com
}

check for

updates

Citation: Kyaw, P.P.; Macdonald, D.W.; Penjor, U.; Htun, S.; Naing, H.; Burnham, D.; Kaszta, Ż.; Cushman, S.A. Investigating Carnivore Guild Structure: Spatial and Temporal Relationships amongst Threatened Felids in Myanmar. ISPRS Int. J. Geo-Inf. 2021, 10, 808. https:// doi.org/10.3390/ijgi10120808

Academic Editor: Wolfgang Kainz

Received: 22 October 2021

Accepted: 28 November 2021

Published: 30 November 2021

Publisher's Note: MDPI stays neutral with regard to jurisdictional claims in published maps and institutional affiliations.

Copyright: (c) 2021 by the authors. Licensee MDPI, Basel, Switzerland. This article is an open access article distributed under the terms and conditions of the Creative Commons Attribution (CC BY) license (https:/ / creativecommons.org/licenses/by/ $4.0 /)$.

\begin{abstract}
The co-occurrence of felid species in Southeast Asia provides an unusual opportunity to investigate guild structure and the factors controlling it. Using camera-trap data, we quantified the space use, temporal activity, and multi-dimensional niche overlap of the tiger, clouded leopard, Asiatic golden cat, marbled cat, and leopard cat in the Htamanthi Wildlife Sanctuary, Myanmar. We hypothesised that the spatio-temporal behaviour of smaller cats would reflect the avoidance of the larger cats, and similar-sized guild members would partition their niches in space or time to reduce resource competition. Our approach involved modelling single-species occupancy, pairwise spatial overlap using Bayesian inference, activity overlap with kernel density estimation, and multivariate analyses. The felid assembly appeared to be partitioned mainly on a spatial rather than temporal dimension, and no significant evidence of mesopredator release was observed. Nonetheless, the temporal association between the three mesopredators was inversely related to the similarity in their body sizes. The largest niche differences in the use of space and time occurred between the three smallest species. This study offers new insight into carnivore guild assembly and adds substantially to knowledge of five of the least known felids of conservation concern.
\end{abstract}

Keywords: activity pattern; co-occurrence; Htamanthi Wildlife Sanctuary; multi-species occupancy; niche partitioning

\section{Introduction}

The science of ecology is underpinned by niche theory [1]. This theory postulates that the distribution, abundance, and survival of organisms is dictated by their fundamental niche, which is defined as an area of essential resources within an n-dimensional hypervolume of multiple environmental variables (e.g., temperature, habitat type, elevation, etc.) and its realised niche, which is the portion of the fundamental niche actually occupied, which is influenced by interaction with other species [2,3]. However, quantifying ecological niches, even for well-studied species, is rarely straightforward [4]. In particular, species interactions among predator-prey and competitor species networks may influence species distribution and abundance and interact strongly with environmental dimensions of the ecological niche. Therefore, niche analysis should account for both environmental and biotic interactions and attempt to quantify the relationships among them. A general postulate of niche theory is that the coexistence of ecologically similar species requires a difference in their realized niches [5].

The assembly of ecological communities is a fundamental topic in ecology. Amongst mammals, guilds of carnivores have been particularly useful in understanding drivers 
of community and guild structure in relation to, for example, character displacement and niche partitioning [6-9] and intra-guild hostility [7,8,10]. Among carnivore taxa, the Felidae offers a particularly relevant model system for understanding niche separation and apparent competition given that all 37 felid species are similar in morphology and behaviour, differing principally in size, and since they occur in many different combinations of species' assembly across a broad range of ecological systems [11].

The combinations of felid species in different communities offer the opportunity to test how a guild functions in the presence and absence of different component species. For example, Oliveira et al. [12] describe niche relationships among 11 sympatric neotropical felid species in South America. Their study observed the possible mesopredator release [13] among neotropical felids. Specifically, they found that ocelot (Leopardus pardalis) density is not affected by larger species such as puma (Leopardus pardalis) and jaguar (Panthera onca), but smaller cats exhibited higher densities as ocelot numbers decrease or in areas where ocelots are not found. A very similar guild, with highly convergent members paralleling those in the Americas, is comprised of up to 12 felid species in Southeast Asia [11]. Hearn et al. [9] modelled spatial and temporal niche structure and partitioning among three Southeast Asian felid species and found clear patterns of displacement related to body size and likely prey preferences in spatial and temporal niche structure. Specifically, Hearn et al. [9] found that smaller felids tend to be separated spatio-temporally from larger mesopredators such as clouded leopards (Neofelis diardi), but the small marbled cat (Pardofelis marmorata) exhibited the lowest spatial partitioning with clouded leopards.

Building on the results of these studies, we aim to explore the patterns and potential drivers of felid niche overlap among multiple species in the Htamanthi Wildlife Sanctuary (HWS) of the Northern Forest Complex (NFC) of Myanmar, where seven felid species co-exist: the tiger, Panthera tigris (Endangered), mainland clouded leopard, Neofelis nebulosa (Vulnerable), Asiatic golden cat, Catopuma teminikii (Near Threatened), marbled cat, Pardofelis marmorata (Near Threatened), common leopard, Panthera pardus (Vulnerable), jungle cat, Felis chaus (Least Concern), and leopard cat, Prionailurus bengalensis (Least Concern). The area is also important for transboundary biodiversity habitat conservation, since it lies at the confluence of three biodiversity hotspots: Eastern Himalaya, Mountains of Southwest China, and Indo-Burma [14], and it is a critical node for regional wildlife connectivity [15]. In addition, research and conservation activities are increasingly shifting from single-species investigations to guild and multi-species investigations (e.g., $[9,16,17])$ not only to understand better the interaction between species but also to better support conservation. Therefore, our objective was to explore intra-guild interactions among mesopredators (clouded leopard, marbled cat, Asiatic golden cat, leopard cat) and the much larger tiger in the Htamanthi Wildlife Sanctuary.

This study is a component of a region-wide research programme centred on clouded leopard $[15,18]$ and the felids with which they co-occur in an aggregated range running from Nepal in the northwest [19] to Kalimantan in the southeast [20]. There have been few studies focused explicitly on species interactions within the felid guild, most of which addressed particular pair-wise interspecific interactions [9,21-23]. Although studies of competition, interactions, and resource partitioning of sympatric Asiatic felids are accumulating $[9,22,24]$, how different-sized members of this felid guild respond to each other is still poorly known, and this was a motivation for our study.

From previous studies (e.g., [9,12]), there seems to be a general pattern of niche displacement in time and space in which species of similar size tend to show the largest niche displacement. We would like to know if there is a displacement of mesopredators by dominant species, such as the tiger, resulting in the suppression of mesosopredator competition. Therefore, we hypothesise that larger cats can influence the spatial and temporal niches of smaller cat species due to predation and interference competition, leading to the displacement of realised niches in time and space. We expected that coexistence of the felid guild would be mediated by behavioural mechanisms such as the segregation of space use and temporal activity pattern [9]. 
Specifically, we had six hypotheses based on body size relationships between the species (Figure 1A,B). (1) We expected that niche separation in space and time, and their intersection, would be associated with differences in body size, such that similarly-sized species would occupy more distinct ecological niches, given their expected higher likelihood of interference competition. (2) We expected that the clouded leopard, golden cat, and marbled cat would show spatial or temporal displacement from the tiger, with the clouded leopard showing the largest displacement, followed by the golden cat and finally marbled cat. This is based on the expectation that the tiger, as the dominant member of the guild, could drive niche separation in this system, with the species most similar in body size to the tiger expressing the largest displacement. (3) We hypothesised that there could be a mesopredator release of the golden cat and marbled cat arising from the displacement of the clouded leopard by tigers, in which case we would expect low overlap between tigers and clouded leopards, but higher overlap between golden cats and marbled cats with tigers. (4) We also expected a niche displacement of both the golden cat and marbled cat, as both sought to avoid the competitively superior clouded leopard, either spatially or temporally, and we expected this displacement to be more marked for the golden cat because of its more similar size to the clouded leopard. (5) Following Hearn et al. [9], who characterised the Sunda clouded leopard (N. diardi) as nocturnal and the marbled cat as diurnal, we expected the displacement between the marbled cat and clouded leopard to be primarily temporal and therefore hypothesised that these species may utilise the same areas but at different times of day without experiencing elevated competition between them. Finally, (6) we predicted that the marbled cat would show the strongest displacement with the golden cat, to which it is most similar in size; furthermore, the marbled cat has been documented to be diurnal and the golden cat to be more cathemeral, so we expected any displacement to be primarily be in the temporal niche dimension. Each hypothesis expresses the expected outcomes of particular interactions between subsets of the guild, assuming all else is equal. In addition, we employ a multivariate analysis approach that evaluates the support for each hypothesis individually and all hypotheses in combination with each other since we expect complicated, cascading interactions between these processes in nature. This enables us to evaluate the pattern of niche separation across multiple potentially interacting hypotheses of niche differentiation in the felid guild of northern Myanmar.

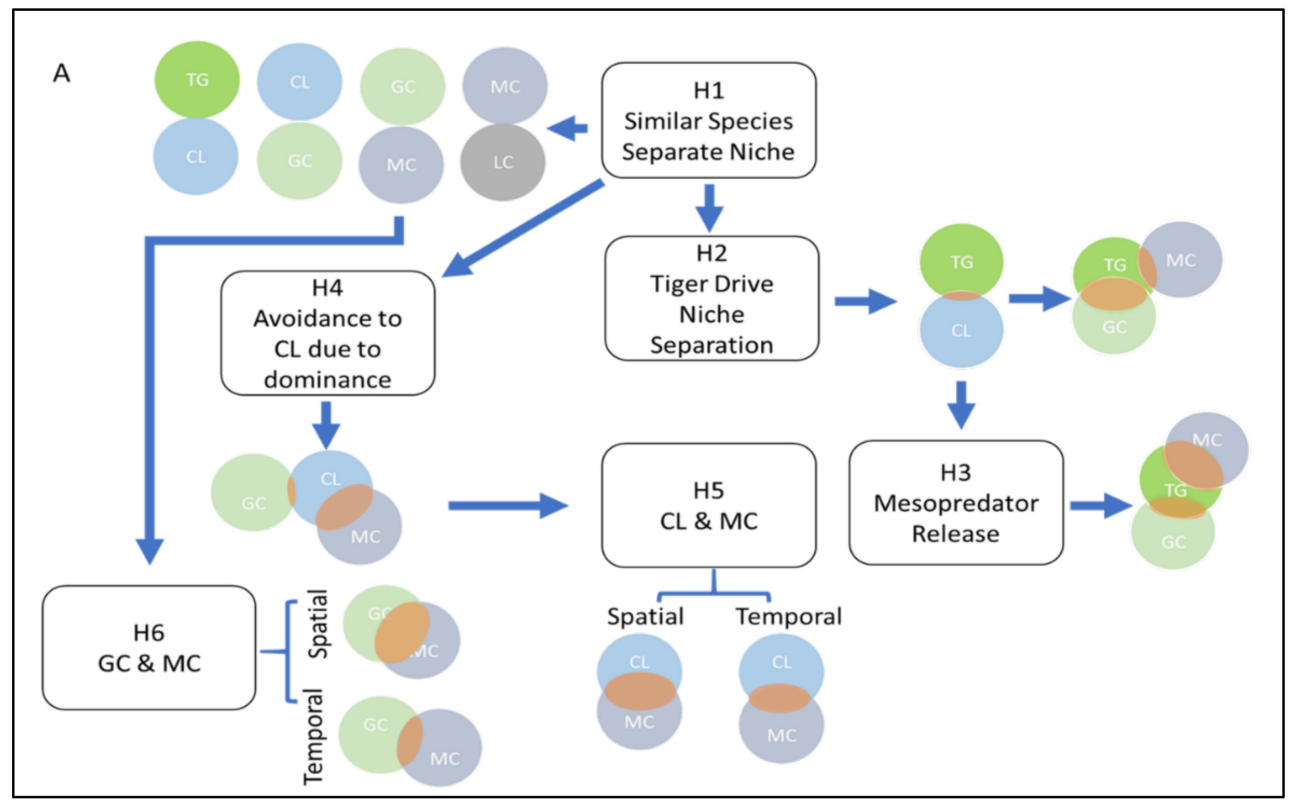

Figure 1. Cont. 


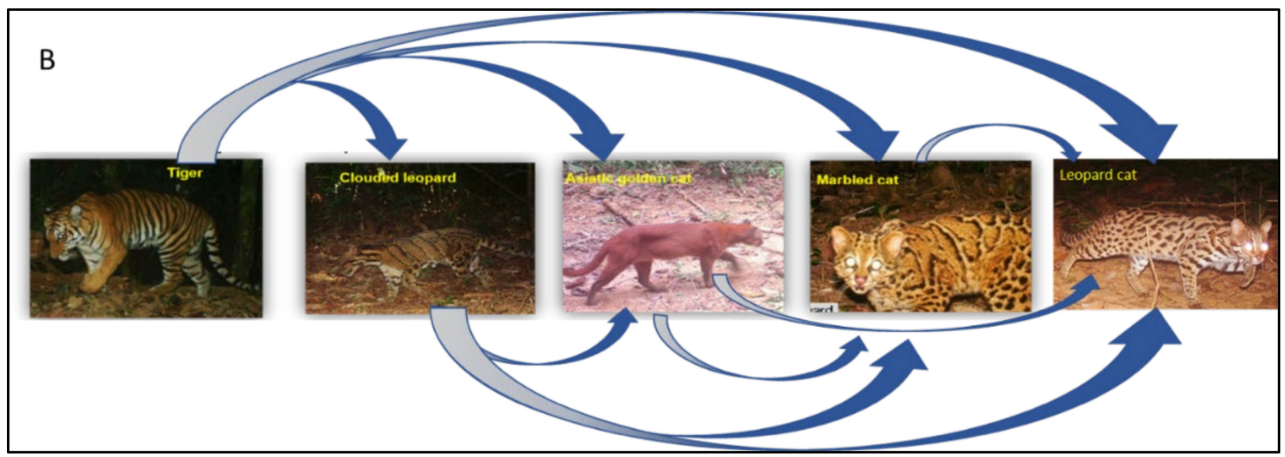

Figure 1. (A) Proposed hypotheses of spatio-temporal interaction among felid species (where TG = Tiger, $\mathrm{CL}=$ Clouded leopard, GC = Asiatic golden cat, $\mathrm{MC}=$ Marbled cat, $\mathrm{LC}=$ Leopard cat, and $\mathrm{H}=$ Hypothesis. The size of overlap of circles (Orange colour) represents greater or lesser spatiotemporal overlap between two species). (B) Proposed model of spatio-temporal influence of larger cats on smaller cat (from left to right: tiger (Panthera tigris), clouded leopard (Neofelis nebulosa), Asiatic golden cat (Catopuma teminckii), marbled cat (Pardofelis marmorata), and leopard cat (Prionailurus bengalensis)) (photos not to scale).

\section{Materials and Methods}

\subsection{Study Area}

The data were collected during camera trap surveys in the Htamanthi Wildlife Sanctuary (HWS) of Myanmar, Southeast Asia (Figure 2), which is the largest protected area in the Sagaing Region of Myanmar $\left(2151 \mathrm{~km}^{2}\right)$. The elevation of HWS ranges from 141 to $618 \mathrm{~m}$, with small undulating hills throughout. Forest types in HWS include semi-evergreen, moist, and dry mixed deciduous forests [25]. A high diversity of threatened Asian large mammal species inhabit HWS, including tigers with a density estimate of $0.81 \pm$ SD 0.40 individuals per $100 \mathrm{~km}^{2}$ [26], dhole (Cuon alpinus), Asiatic black bear (Ursus thibetanus), Asian elephant (Elephas maximus), gaur (Bos gaurus), and, previously, Sumatran rhino (Dicerorhinus sumatrensis) (Hundley, 1952; cited in [27]). The eastern and western borders of the HWS abut rural communities. The sanctuary was being considered for a dam construction project and consequently was being exploited by logging companies until 2012. While that project was cancelled, numerous threats remain (e.g., poaching, illegal logging, and artisanal gold mining). For law enforcement and management purposes, the sanctuary is divided into four management zones from north to south: Nam Phi Lin, Nam E Zu, Nam Pa Gon, and Nam Yan Yin (Figure 2).

\subsection{Camera Trap Surveys}

Camera trap surveys were undertaken from 2014 to 2018. These surveys were conducted by the Nature and Wildlife Conservation Division of the Forest Department and the Wildlife Conservation Society Myanmar in collaboration with the Wildlife Conservation Research Unit (WildCRU) of the University of Oxford, International Union for Conservation of Nature (IUCN), and Foundation Segre. Each year, survey areas were selected for each survey to avoid spatial overlap of camera grids and to maximise the inter-annual coverage. In total, five survey grids were monitored with seven surveys in the HWS. Due to some differences in target species and procedures between surveys, there were variations in the numbers of camera stations and trapping duration, but overall, the spacing between each camera station ranged from 319 to $2528 \mathrm{~m}$ (mean $=1324.9$ with SE \pm 27.01$)$. Except for that targeting sun bears, all surveys used paired camera traps at each station (Table S1 in the Supplementary Materials documents the details of numbers of planned and working camera stations, and target species for each survey). 


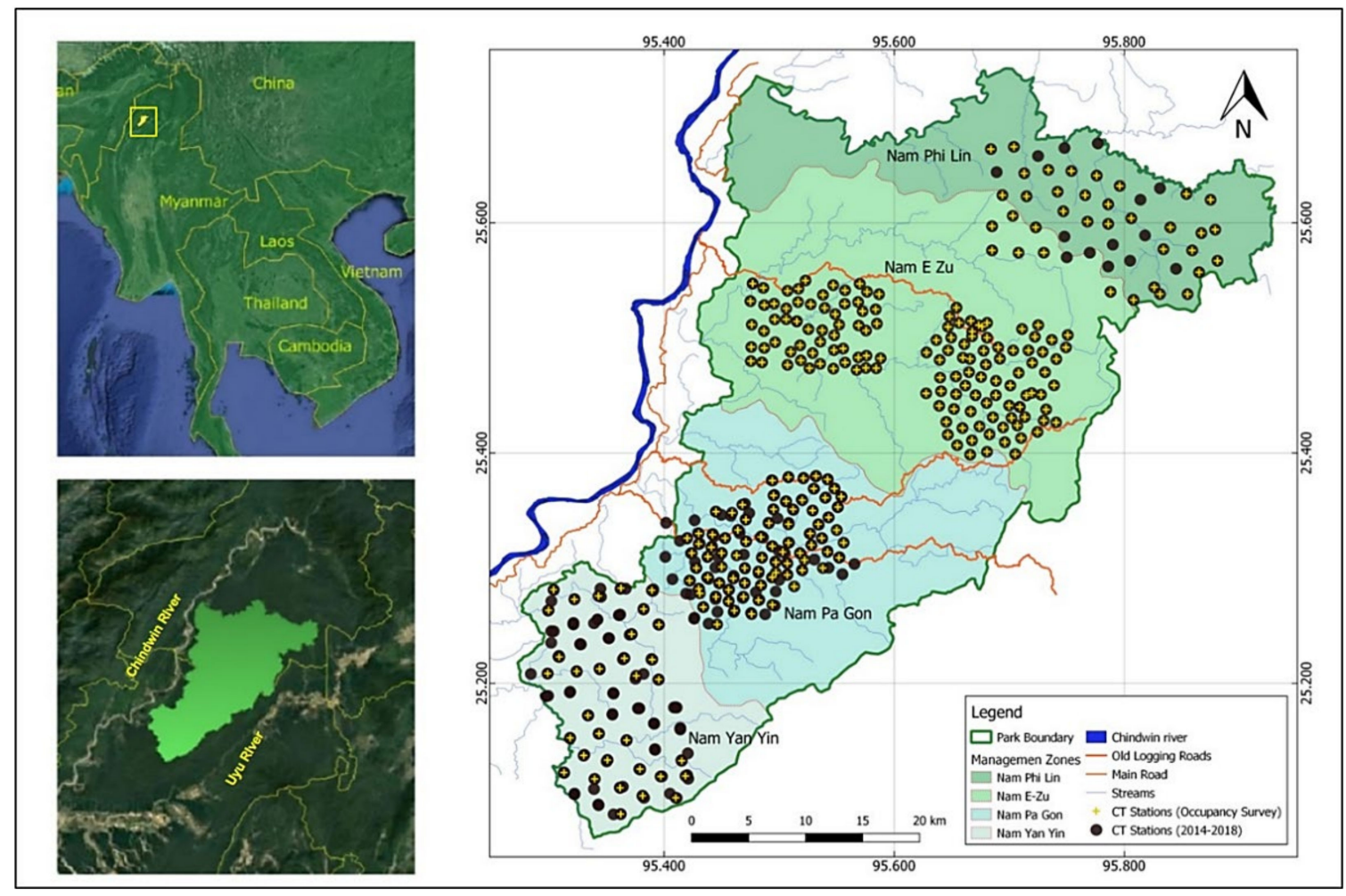

Figure 2. Camera trap surveys in Htamanthi Wildlife Sanctuary. A total of 525 camera trap stations (black dots) have been deployed and surveyed across the sanctuary (2014-2018); 288 camera stations (yellow stars) were used in space use analysis.

Camera trap image metadata extraction was carried out using the "Exif file extractor" [28] and the "Panthera camera trap file manager" software [29,30]. Animals photographed were identified manually and tagged with relevant metadata. From 2017, a camera trap data management and analysis package (CTAP), developed by the Zoological Society of London (ZSL) [31], was used to compile and summarise yearly camera trap data. The non-uniformities in date and time formats, species names, and field surveys were also standardised using the CTAP package in ZSL software. We excluded the common leopard and jungle cat from our model, since only two leopard individuals and one photo of a jungle cat were observed in our survey.

\subsection{Space Use and Species Interaction}

From a total of 525 camera trap stations, we excluded 32 faulty stations and 205 repeated stations. To conform with single-season model design, we used only those stations that were surveyed once; thus, the remaining 288 were chosen for space use analysis. Occupancy modelling assumes the closure of populations [32], whereas our analyses amalgamate data from surveys in different years and different sectors of the study site. Furthermore, since different surveys targeted different species (tiger, clouded leopard, sun bear) in different sites, the criteria of independence between sites and of spatial autocorrelation might also be violated. However, these assumptions are all relaxed when occupancy is interpreted as a "probability of space use" [33]. Although our main objective is to estimate the interactions between the five felid species over space use, we nonetheless applied an initial occupancy modelling framework to identify the most meaningful set of covariates affecting the probabilities of individual species' space use (Method S1 and Figure S1 in Supplementary Material document how this was done by single-species occupancy modelling and present the model outputs).

We estimated the overlap in space use of the five felid species using multi-species occupancy modelling based on the approach by Bischof [34], which modified the Bayesian inference method by Waddle et al. [35]. This multi-species model assumes asymmetric interactions between dominant and subordinate species, where the presence of subordinate 
species is dependent on the presence of dominant species but not vice versa [35]. This also enables the simultaneous estimation of both space use and detection probability of multiple species while allowing for interspecific interactions and covariate effects. Our model includes the following interactions: (a) tiger habitat use affecting clouded leopard, marbled cat, Asiatic golden cat, and leopard cat; (b) clouded leopard affecting marbled cat, Asiatic golden cat, and leopard cat; (c) Asiatic golden cat affecting marbled cat, and (d) Asiatic golden cat and marbled cat affecting leopard cat (Figure 1B). In this analysis, we estimated the overlap or avoidance of each pair of species, while accounting for environmental and anthropogenic effects, which was an approach demonstrated to reveal biologically meaningful results [34]. Figure 3 presents the workflow used to estimate space use and spatial interactions between felids.

\section{Single-species occupancy model}

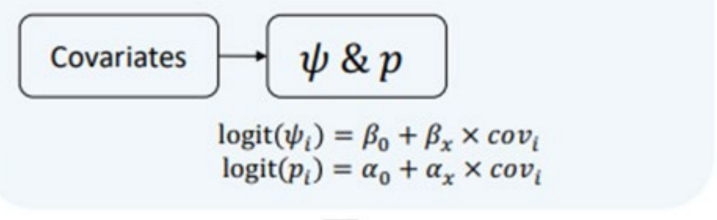

Relevant covariates

\section{Multi-species occupancy model Asymmetric interaction}

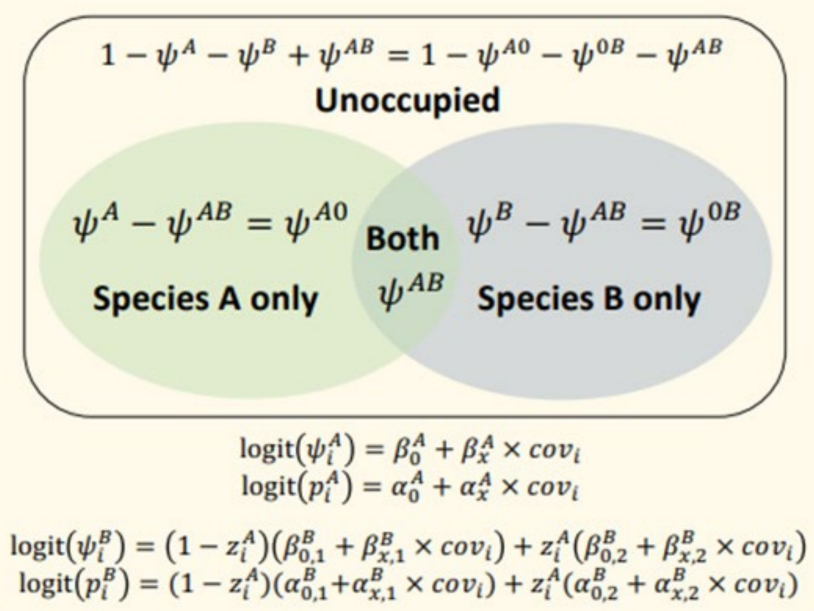

Figure 3. Workflow depicting single-species, single-season model (top), and multi-species asymmetrical interaction occupancy model (bottom). Single-species occupancy models were used to identify best covariates for each species. Multi-species occupancy models were used to examine the probability for each occupancy state (coloured Venn diagrams). The green ellipse represents the probability that the species A occupies a site irrespective of species B, and the grey ellipse represents the probability that species B occupies the site irrespective of species $\mathrm{A}$. The intersection represents the probability that the site is occupied by both species.

From single-species occupancy modelling (Method S1, Supplementary Material), we identified six covariates: distance to park boundary, human disturbance, elevation, percent tree cover, distance to main streams (used by boats), and density of streams, which were used as site covariates in the multispecies model. For all species, we modelled detection 
probability as a function of survey effort, which was measured as the number of days the camera was deployed. For all species except tiger, we used all site covariates, whereas for the tiger, we used distance to boundary, disturbance, mean elevation, and tree cover.

For prior occupancy for interacting species, we used the normal distribution function (with mean $=0$, standard deviation $=1.4$ ) as suggested by Northrup et al. [36]. Our sensitivity analyses with different values of SD indicated this prior to yield sensible estimates (Figure S2, Supplementary Materials). To quantify overlap and avoidance, we used the logodds and 95\% credible interval of the posterior distribution of parameter estimates [22,34]. We ran the model with four parallel chains of 300,000 Markov Chain Monte Carlo (MCMC) iterations each and discarded 50,000 as burn-in and thinning at the rate of 5 while allowing for chains to stabilise. We checked the model convergence with $\hat{R}$ values (the value of which <1.1 indicates convergence [37] and MCMC trace plots [38]). We used the "R2jags" package in R [39,40] to call JAGS [41] to fit our models.

\subsection{Temporal Activity and Overlap}

Two different datasets were used to study the overlap of temporal activity. Firstly, we pooled all the camera trap data obtained from all 493 working camera trap stations, of which 312 stations detected our study species. Secondly, we used the subset of data from the spatial analysis where 199 out of 288 stations detected our study species. Therefore, we obtained two datasets containing different numbers of independent total observations for all species $(n=1344$ and $n=823)$. Lynam et al. [42] advised caution in interpreting the results of temporal overlap analysis from small surveys. Thus, we analysed both datasets separately to compare the activity patterns and overlap to check the representativeness of activity patterns. We assumed that individuals of each species had an equal chance of being photographed when they were active [43]. A capture by camera was described as "activity" regardless of the behaviour that could be determined in the camera trap image. We regarded consecutive photographs of the same species at a station within 30 min as one event. The first detection in any 30-min window was retained and considered independent. Based on local time, diurnal activity was defined as 07:00-17:59 and nocturnal activity was defined as 20:00-04:59. Crepuscular activity was regarded as 05:00-06:59 (dawn) and 18:00-19:59 (dusk).

Diel activity was explored by comparing and overlapping the activity patterns of clouded leopards, tigers, marbled cats, Asiatic golden cats, and leopard cats with kernel density plots (e.g., [9]). Although histograms are widely used to estimate probability density functions, kernel estimators have the advantage of being intuitive to interpret, simple to analyse mathematically, and more efficient $[9,44]$. Thus, we constructed Von Mises kernel density plots corresponding to the circular distribution of diel data. Since smoothing can affect the estimation of activity overlap, we tested the sensitivity by using different bandwidth values $(c=1, c=0.5$, and $c=0.1)$ and compared the bootstrap means and confidence intervals (Table S6 in Supplementary Materials). For overlap, we used the 'Dhat4' estimator for species-pairs with sample size $>75$ and the 'Dhat1' estimator for pairs including sample size $<75$ [45]. We obtained confidence intervals as percentiles from 10,000 bootstrap samples. All the statistical analyses were carried out using the "overlap" package [46] in $\mathrm{R}$ [40].

\subsection{Multi-Dimensional Spatio-Temporal Overlap}

In addition to spatial and temporal overlap analyses, we also computed an index for multi-dimensional overlap. For each species, we multiplied the spatial overlap with the time overlap estimates to obtain the total overlap expected in space and time simultaneously. This gives the total overlap expected in space and time simultaneously (e.g., will the animal be active in the same place at the same time). 


\subsection{Multivariate Evaluation of Support for All Hypotheses}

We used Mantel tests [47] to evaluate the support for each hypothesis individually and all hypotheses in interaction. The Mantel test is a correlation between distance matrices. The dependent variable matrices in this test were the pairwise overlap matrices among the five species for overlap in (1) space, (2) time, and (3) jointly in space and time. The independent variable matrices were model matrices [48] representing the expectation of each hypothesis (Table S8, Supplementary Material). The correlation between the overlap observed among pairs of species and the expected pattern of dissimilarity among species in each hypothesis gives a quantitative measure of the support for each individual hypothesis. In addition, by computing the summed combinations of all model matrices among hypotheses, we are able to test the joint support for multiple hypotheses simultaneously (e.g., [49]). We ranked combined hypotheses based on the magnitudes of the Mantel correlation (e.g., [50]), and assessed statistical significance based on 100,000 matrix permutations [48].

We computed 64 combined hypotheses as the combinations of the six individual hypotheses articulated in the Introduction section. We evaluated the support for each of these using Mantel tests between the pairwise overlap matrices in space, time, and jointly in space and time among all pairs of species and the model matrix corresponding to that hypothesis (Table S9, Supplementary Material). For each of the spatial, temporal, or joint overlaps, we ranked the hypotheses by Mantel $r$ value. We discuss only those that meet significance thresholds at three alpha levels $(0.05,0.1,0.2)$. Given the low power in Mantel testing on small matrices, such as those resulting from the combination of only five species, the magnitude of the Mantel $r$ statistic is likely more informative than significance testing (e.g., [51]), and a more liberal alpha level is recommended when significance testing is used. We evaluate and discuss hypotheses that have support at the 0.2 alpha level, and we also discuss those supported at 0.1 and 0.05 with increasing confidence.

\section{Results}

\subsection{Space Use}

From a total of 288 camera trap stations, five felid species were detected in sufficient numbers to sustain spatial interaction analysis: tigers (31 stations), clouded leopard (98 stations), Asiatic golden cat (80 stations), marbled cat (52 stations), and leopard cat (75 stations). We estimated ten pair-wise intersections of space use between five sympatric felid species based on a pair-wise multi-species interaction model (Figure 4). Almost all species showed spatial interaction with each other. The leopard cat space use was highly associated (from $95 \%$ to $100 \%$ of overlap) with that of all the larger felids (Figure 4). Only the marbled cat showed slight avoidance (58\% overlap) with the Asiatic golden cat. The marbled cat also showed weak avoidance of larger species (e.g., Asiatic golden cat, clouded leopard, and tiger). The initial single species occupancy outputs (Tables S2-S4), the JAGs model output (Table S5), posterior distributions and associated uncertainties of the co-occurrence models (Figure S3) are detailed in the Supplementary Material.

\subsection{Activity Pattern and Temporal Overlap}

Tiger and marbled cats were primarily diurnal in our study area (73\% and $83 \%)$, while clouded leopards were mostly nocturnal ( $37 \%$ diurnal activity), with activity peaks observed during 03:00 and 04:00 h. Asiatic golden cats tended to be cathemeral and were active during both night and day ( $45 \%$ diurnal). The leopard cat was active in $53 \%$ of the day period with highest peaks of activity early in the night and before dawn. Table S7 in the Supplementary Material tabulates a summary of the activity patterns revealed by our own study and others in neighbouring countries. 


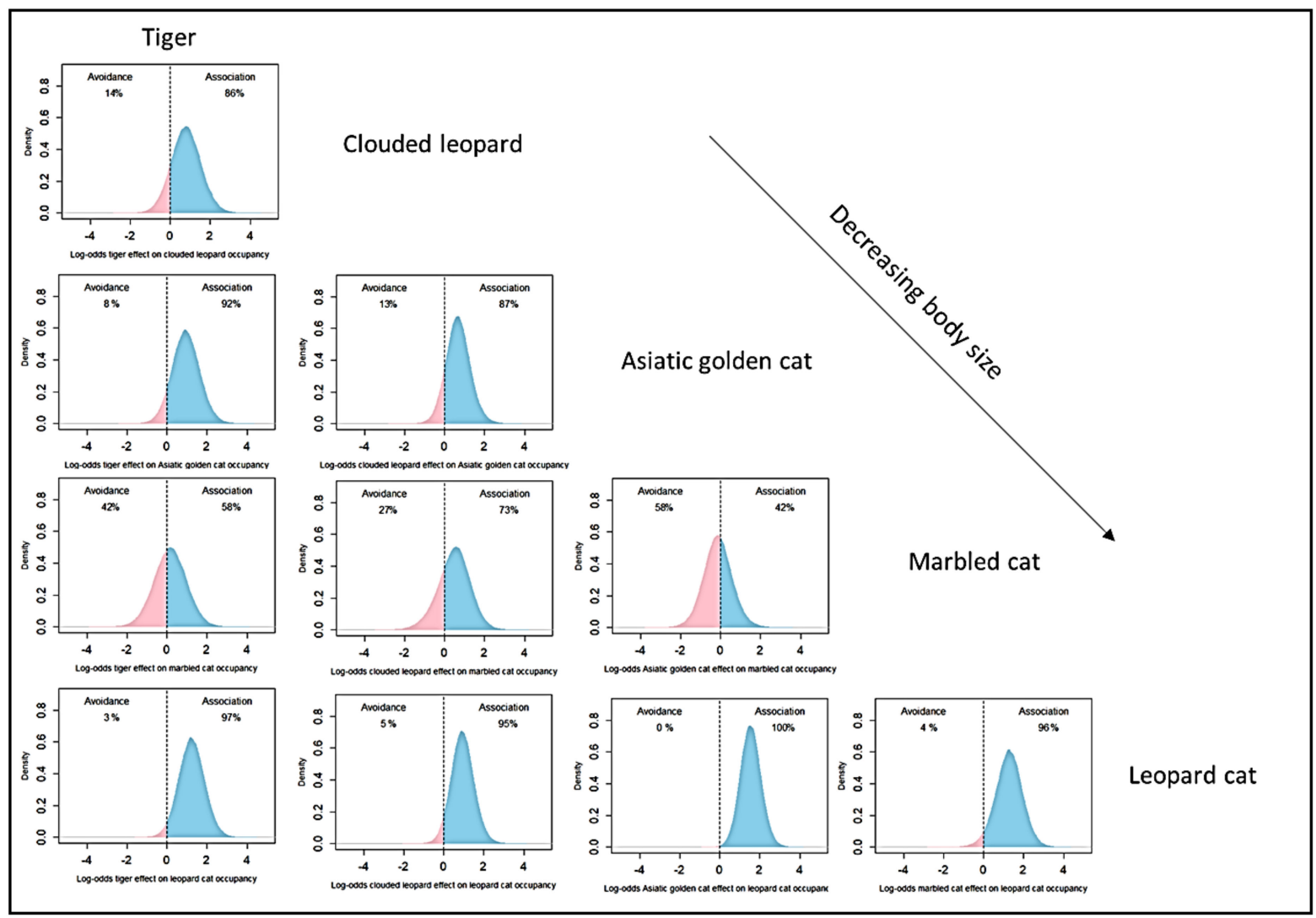

Figure 4. Spatial association and avoidance between tiger, clouded leopard, Asiatic golden cat, marbled cat, and leopard cat based on a multi-species spatial interaction model. This shows the log-odds ratio of dominant species to subordinate species (Blue shade: Probability of association, Pink shade: Probability of avoidance).

Tigers and marbled cats exhibited the most similar activity patterns of any pairing, with the highest coefficient of temporal overlap for both datasets $(\Delta 1=0.88$ for $n=823$ and $\Delta 4=0.89$ for $n=1344$ ) (Table 1 and Figure 5). The two smallest species, the marbled and leopard cats exhibited the strongest temporal segregation $(\Delta 4=0.27$ and $\Delta 4=0.29)$, reflecting their different diel activities. In addition, leopard cats had low temporal overlap with tigers $(\Delta 1$ and $\Delta 4=0.36)$. Several pairings had relatively high overlaps in activity around the crepuscular periods of 6:00 and 18:00. Values for the overall overlap coefficient and in the activity patterns were similar for the two datasets $(n=1379$ and $n=844)$ (Table 1$)$. We validate our diagnoses through a comparison of diel activities calculated from the two datasets and the overlap coefficient plot displayed in Figures S4 and S5. Our findings concur with those in the literature for these same felids in different regions (Table S7, Supplementary Material).

Table 1. Coefficient of overlap in activity pattern of the tiger, clouded leopard, marbled cat, Asiatic golden cat, and leopard cat with 95\% confidence intervals for both different sample sizes, $n=823(\Delta 1)$ and $n=1344(\Delta 4)$.

\begin{tabular}{|c|c|c|c|c|c|c|c|c|}
\hline & \multicolumn{2}{|c|}{ Clouded Leopard } & \multicolumn{2}{|c|}{ Asiatic Golden Cat } & \multicolumn{2}{|c|}{ Marbled Cat } & \multicolumn{2}{|c|}{ Leopard Cat } \\
\hline & $n=823(\Delta 1)$ & $\begin{array}{c}n=1344 \\
(\Delta 4)\end{array}$ & $\begin{array}{c}n=823 \\
(\Delta 1)\end{array}$ & $\begin{array}{c}n=1344 \\
(\Delta 4)\end{array}$ & $\begin{array}{c}n=823 \\
(\Delta 1)\end{array}$ & $\begin{array}{c}n=1344 \\
(\Delta 4)\end{array}$ & $\begin{array}{c}n=823 \\
(\Delta 1)\end{array}$ & $\begin{array}{c}n=1344 \\
(\Delta 4)\end{array}$ \\
\hline $\begin{array}{c}\text { Tiger } \\
\text { Clouded leopard } \\
\text { Asiatic golden cat } \\
\text { Marbled cat }\end{array}$ & $\begin{array}{c}0.6 \\
(0.48-0.72)\end{array}$ & $\begin{array}{c}0.54 \\
(0.45-0.63)\end{array}$ & $\begin{array}{c}0.68 \\
(0.57-0.78) \\
0.83 \\
(0.75-0.90)\end{array}$ & $\begin{array}{c}0.68 \\
(0.59-0.76) \\
0.79 \\
(0.72-0.85)\end{array}$ & $\begin{array}{c}0.88 \\
(0.77-0.97) \\
0.525 \\
(0.44-0.61) \\
0.59 \\
(0.51-0.67)\end{array}$ & $\begin{array}{c}0.89 \\
(0.81-0.97) \\
0.48 \\
(0.41-0.55) \\
0.60 \\
(0.54-0.67)\end{array}$ & $\begin{array}{c}0.36 \\
(0.26-0.47) \\
0.73 \\
(0.65-0.79) \\
0.64 \\
(0.57-0.08) \\
0.273 \\
(0.20-0.35)\end{array}$ & $\begin{array}{c}0.362 \\
(0.27-0.44) \\
0.79 \\
(0.74-0.85) \\
0.664 \\
(0.61-0.72) \\
0.29 \\
(0.24-0.36)\end{array}$ \\
\hline
\end{tabular}




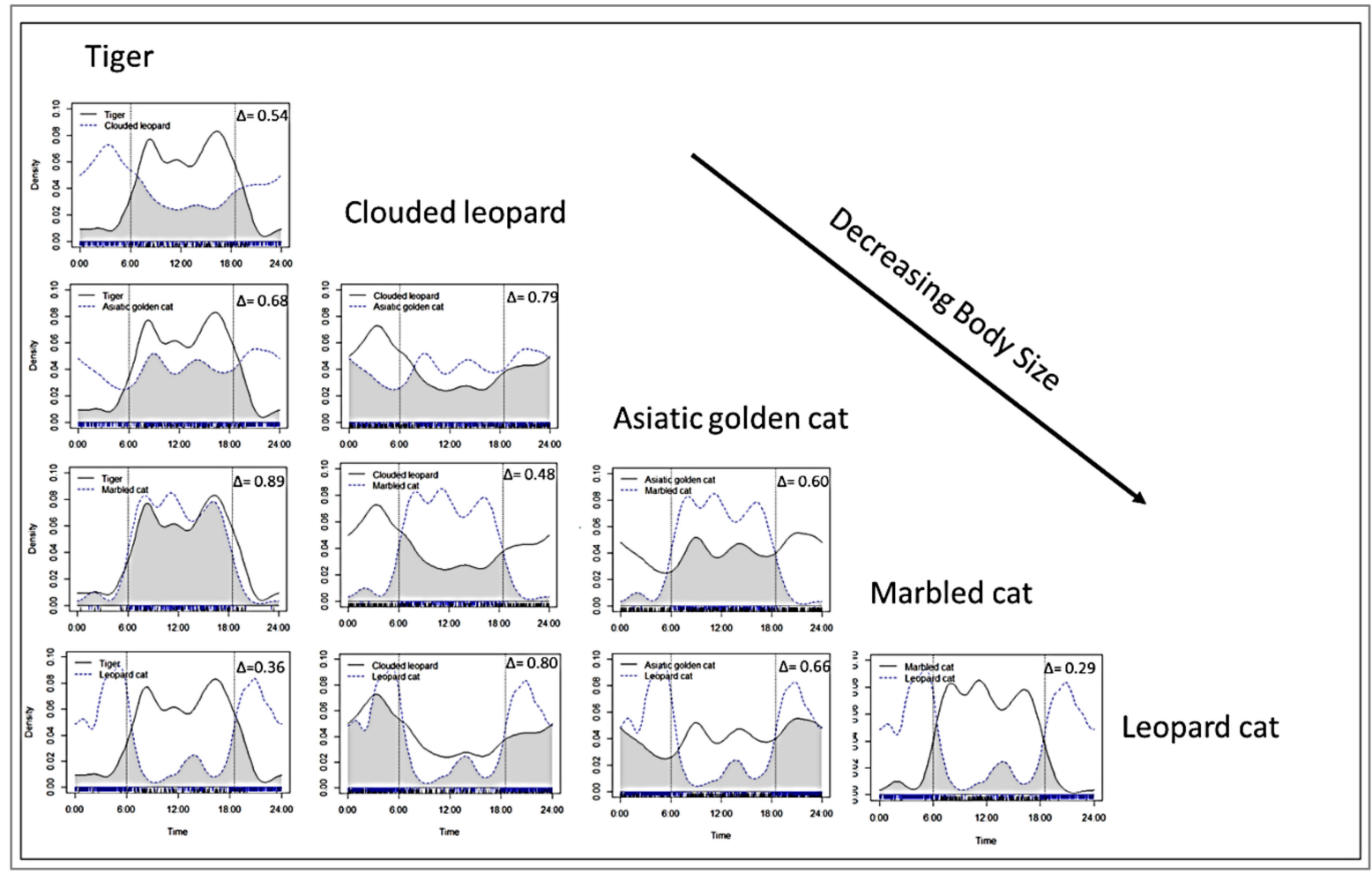

Figure 5. Activity overlap of the tiger, clouded leopard, marbled cat, and Asiatic golden cat from all camera trap stations $(n=1344)$. Dotted vertical lines at 06:00 and 18:00 represent the approximate dawn and dusk. Activities detected for each species are represented by blue and black coloured rugs on the x-axes.

\subsection{Multi-Dimensional Spatio-Temporal Overlap}

The clouded leopard and leopard cat had the highest multi-dimensional niche intersection (0.76), which was followed by the clouded leopard and golden cat (0.69). By far, the lowest total intersection was between the Asiatic golden cat and marbled cat (0.25) (Table 2). As the two species most similar in size, the marbled and leopard cats also exhibited low intersection (0.28) as did, to a lesser extent, tiger-leopard and clouded leopard-marbled cat pairs (0.35).

Table 2. Index of niche overlap: spatial, temporal, and multi-dimensional overlap (index of niche overlap as a multiplication of spatial and temporal overlap) between each pair of species.

\begin{tabular}{cccc}
\hline Paired Species & Spatial Overlap & Temporal Overlap & Index of Niche Overlap \\
\hline Asiatic golden cat-Marbled cat & 0.42 & 0.6 & 0.25 \\
Marbled cat-Leopard cat & 0.96 & 0.29 & 0.28 \\
Tiger-Leopard cat & 0.97 & 0.36 & 0.35 \\
Clouded leopard-Marbled cat & 0.73 & 0.48 & 0.35 \\
Tiger-Clouded leopard & 0.86 & 0.54 & 0.46 \\
Tiger-Marbled cat & 0.58 & 0.89 & 0.52 \\
Tiger-Asiatic golden cat & 0.92 & 0.68 & 0.63 \\
Asiatic golden cat-Leopard cat & 1 & 0.66 & 0.66 \\
Clouded leopard-Asiatic golden cat & 0.87 & 0.79 & 0.69 \\
Clouded leopard-Leopard cat & 0.95 & 0.8 & 0.76 \\
\hline
\end{tabular}




\subsection{Multivariate Analysis of Hypothesis Support}

For the analysis of the spatial overlap among felid occurrence, 16 combined hypotheses were significant at the 0.2 level, nine were significant at the 0.1 level, and two were significant at the 0.05 level. All of these had very large support based on the magnitude of the Mantel correlations, which was large $(\mathrm{Mr}>0.5)$ and indicated strong linear relationships between the spatial overlap and the model matrices in these 16 hypotheses (Table S9 in Supplementary Material, Table 3). Table 3 reports the proportion of supported models at each alpha level containing each of the six individual hypotheses. Hypothesis 6 is included in all supported hypotheses at all three alpha levels. Hypotheses 5, 4, 2, and 1 received partial support for partitioning on the spatial niche dimension, with $50 \%$ of models supported at alpha 0.2 including these hypotheses. Hypothesis 5 was included in all models supported at the 0.05 level, and the most supported single hypothesis based on significance of support is the joint effect of hypotheses 5 and 6 on spatial overlap patterns among species. Hypothesis 3 was not included in any supported models at any significance level for spatial overlap, and hypothesis 4 was poorly supported at the higher significance levels (0.1 and 0.05). Hypothesis 2 was supported in half of the models supported at the highest (0.05) significance level.

Table 3. Proportion of all hypotheses including each of the six individual hypotheses significant at three alpha levels (0.05, 0.1 , and 0.2 ) for the spatial niche partitioning analysis.

\begin{tabular}{ccccccc}
\hline Alpha Level & Hypothesis 6 & Hypothesis 5 & Hypothesis 4 & Hypothesis 3 & Hypothesis 2 & Hypothesis 1 \\
\hline 0.2 & 1 & 0.5 & 0.5 & 0 & 0.5 & 0.5 \\
0.1 & 1 & 0.556 & 0.111 & 0 & 0.556 & 0.444 \\
0.05 & 1 & 1 & 0 & 0 & 0 & 0.5 \\
\hline
\end{tabular}

No hypotheses were significant at the $0.2,0.1$, or 0.5 alpha thresholds for temporal overlap analysis (Table S9, Supplementary Material). No correlations between pair-wise temporal overlap and any of the 64 model matrices were greater than 0.25 , indicating weak relationships between patterns of temporal overlap among the activity patterns of the five pairs of species and any of the hypotheses independently or jointly.

In the analysis of the joint overlap in both spatial and temporal dimensions, 14 models were supported at the 0.2 alpha level, four were supported at 0.1 , and one was supported at 0.05 (Table S9, Supplementary Material). These had moderate support based on the magnitude of the Mantel correlation (all greater than 0.32), but none was as large as the largest Mantel correlations between the spatial dimension of overlap and niche displacement hypotheses (Table S9). Hypothesis 6 was included in all supported hypotheses at all three significance levels (Table 4). Hypothesis 5 was supported in the majority of models at the 0.2 alpha level and was included in the only temporal overlap model supported at the 0.05 level. Hypothesis 1 was also included in the temporal model supported at the 0.05 level. In contrast to the spatial overlap analysis, there was some, but weak support, for hypothesis 3 in the joint space-time overlap analysis (Table 4).

Table 4. Proportion of all hypotheses including each of the six individual hypotheses significant at three alpha levels (0.05, 0.1 , and 0.2 ) for the combined spatial-temporal niche partitioning analysis.

\begin{tabular}{ccccccc}
\hline Alpha Level & Hypothesis 6 & Hypothesis 5 & Hypothesis 4 & Hypothesis 3 & Hypothesis 2 & Hypothesis 1 \\
\hline 0.2 & 1 & 0.714 & 0.143 & 0.571 & 0.286 & 0.5 \\
0.1 & 1 & 0.4 & 0 & 0.2 & 0 & 0.4 \\
0.05 & 1 & 1 & 0 & 0 & 0 & 1 \\
\hline
\end{tabular}




\section{Discussion}

\subsection{Multi-Model Evaluation of Hypotheses}

Collectively, our findings suggest that the main patterns of niche separation among the felid guild in northern Myanmar are spatial and not temporal based on a quantitative comparison among hypotheses. Specifically, while there were several large temporal differences between particular pairs of species (marbled cat-leopard cat and tiger-leopard cat) in terms of spatial and temporal interaction results, none of our a priori hypotheses were supported in the temporal niche dimension, while several were in the spatial dimension. We demonstrate strong support for hypothesis 6 in particular, and 5 and 6 together, in predicting the spatial partitioning and the joint space-time partitioning pattern among pairs of species. The partitioning between the golden cat and marbled cat was most pronounced and statistically significant in the spatial dimension. We had expected a large temporal displacement between these species based on published activity patterns, but we found relatively low temporal separation of the activity patterns. Additionally, we found strong and significant partitioning between the marbled cat and clouded leopard in the spatial dimension but, again, not in the temporal dimension.

There is a general pattern in our results of increasing displacement with decreasing difference in body size in the spatial dimension of the niche structure. The support for both hypothesis 1 and hypothesis 2 in the spatial and space-time overlap, respectively, suggests that the tiger may indeed play a dominant role driving the displacement of subordinate species (hypothesis 2). In addition, there is a general pattern of larger spatial segregation among species of more similar body size; in particular, the dyads of golden cat-marbled cat and clouded leopard-marbled cat are the most highly divergent.

Interestingly, we found little support in either the spatial and temporal dimensions of partitioning for hypothesis 4 and no support in the spatial dimension for hypothesis 3 . There was no support for mesopredator competitive release of the golden cat and marbled cat resulting from the displacement of the clouded leopard by the tiger in the spatial dimension at any of the three alpha levels. However, there was some support for the joint spatial and temporal overlap. This suggests that there is no mesopredator competitive release of the marbled cat and golden cat due to the displacement of the clouded leopards by tigers in space, but there may be displacement in time and space jointly that may reduce the overlap of the marbled cat and golden cat with the clouded leopard, which may alleviate interference competition. The weak support for these two hypotheses suggests overall that there is not a strong niche separation between the clouded leopard and either golden cat and marbled cat (although see hypothesis 5 showing pair-wise separation between the clouded leopard and marbled cat), and that any displacement that exists cannot be explained by mesopredator release by displacement of the clouded leopard by the tiger.

Our results strongly suggested that the niches of the golden and marbled cats, which are two of the smaller felid species, exhibited the greatest niche displacement. The results may indicate that the larger cats all niche-pack to utilize the most abundant prey resources for species of middle to large size. In contrast, our results suggest that the marbled cat, being smaller and semi-arboreal [52], may be adapted to utilize a different prey base available in different space or time, or it may be displaced, perhaps especially by the golden cat, to suboptimal conditions providing lower resource availability. Furthermore, although the golden cat is closer to the marbled cat in weight, the slightly larger clouded leopard is closest to the marbled cat in anatomy, so one cannot assume that the potential for competition, or intra-guild hostility, is only determined by weight. Indeed, we found support for niche separation between the marbled cat and clouded leopard and not between the clouded leopard and golden cat, suggesting other factors, such as morphology and behaviour, may affect this displacement in addition to body size alone.

We hypothesised that tiger presence reduces clouded leopard numbers and/or displaces them, thereby releasing the two smaller mesopredators, golden cats and marbled cats, from suppression by clouded leopards [53]. We hypothesised that competitive release would apply to both the golden cat and marbled cat if dominance by the tiger of the clouded 
leopards in turn reduced downward pressure on the other two. Our results suggest that the largest effect of competition on niche displacement may be between golden and marbled cats, and there is no evidence of competitive release. A plausible explanation may be that given its smaller size and more agile anatomy, the marbled cat is better adapted to, and therefore retreats into, its own favoured realised niche, or that it is competitively displaced out of the niche space dominated by the golden cat and into a less optimal niche (Table 2).

Our results also showed that the clouded leopard and golden cat had the highest total overlap, while the clouded leopard and marbled cat had intermediate overlap. This does not suggest decisive displacement of these two species by the dominant clouded leopard. Rather, it appears that there is a partial displacement along different niche dimensions: the clouded leopard overlapped less in space, but more in time, with the golden cat than with the marbled cat, and the clouded leopard/marbled cat dyad exhibited the greatest overlap in time and least in space of any pairing. These partial displacements are further separated along the dimensions of weight and anatomy. Similar evidence of competitive displacement in a parallel, neotropical, felid guild was reported by Oliveira et al. [12], who concluded that ocelots (Leopardus pardalis) affect the dynamics of smaller felids more strongly than did the largest member of the guild, the jaguar. However, based on the pattern of our multivariate hypothesis modelling, we conclude that the clouded leopard's potential competition with the marbled cat and golden cat is not extensive, whereas the golden cat and marbled cat are clearly the most segregated pairing.

Hearn et al. [9] (see also [54]) reported that Sunda clouded leopards are nocturnal, whereas marbled cats are diurnal, and so one of our hypotheses predicted that segregation on the temporal dimension would suffice to ameliorate competition, and therefore that the two species would not be displaced spatially. Our results do not strongly support this, with moderate overlap spatially (not unexpectedly large) and moderate temporal overlap (low but not statistically significant). This suggests that consistent with our expectation, there is a relatively low temporal overlap and somewhat higher spatial overlap between the clouded leopard and marbled cat, but this is not a strong relationship.

In total, these results suggest a complex pattern of guild assembly and potential competition leading to strong niche displacement between the golden cat and marbled cat but high overlap for the relatively similarly-sized clouded leopard-golden cat and the markedly differently sized tiger-golden cat. This suggests that intra-guild competition is not leading to behavioural displacement according to space or time between the species most likely to compete based on body size alone (clouded leopard and golden cat, clouded leopard and tiger). Rather, the salient displacement is between all three of the larger species and the smaller marbled cat. The marbled cat is anatomically, and in its patterned pelage, a diminutive replica of the clouded leopard, and Hearn et al. [9] suggested that the marbled cat may have a strong dietary preference for avian prey, while the other species are mostly predators of terrestrial quadrupeds. This might lead to substantial niche differentiation to optimize foraging.

Although we evaluated the individual and combined effects of multiple potential hypotheses of niche separation and found support for some and no support for others, the observational and correlational nature of this study does not demonstrate causality. Therefore, future research using manipulative or comparative mensurative [55] experiments should be undertaken to disentangle the multiple possible explanations of observed niche differentiation in the felid guild. The only way reliably to separate the multiple possible explanations of observed niche separation would be to implement experimental studies where some guild members are excluded [56] or to conduct natural experiments replicated in multiple landscapes with different species combinations [57]. However, the observed patterns we saw can exclude possible hypotheses (where displacement was not seen) and provide support for the possibility of others (where displacement was seen consistent with expectations). Given the difficulty of conducting controlled experiments and species exclusion studies on endangered and rare carnivores, experimental studies are unlikely. However, meta-replicated studies repeating niche overlap analysis across the ranges of 
these species and in multiple locations where different combinations of species are present are plausible and would enable more definitive inference about the potential drivers of observed nice separation among these members of the felid guild.

\subsection{Conservation Implications}

The HWS was selectively logged for timber during the decade prior to our study. The high relative space used by the clouded leopard suggests that it may be more tolerant of habitat modification associated with human disturbance and potential exploitation than the tiger. This is broadly consistent with previous reports of clouded leopards occurring in secondary forest [9]. However, in contrast to these previous studies, we found no evidence of the clouded leopard selectively using forest edges (e.g., $[58,59]$ and for the Sunda species $[9,22])$. Proximity to the main streams had little effect on the predicted space use of any of the species in our model; however, we note the lack of tiger tracks and signs near the main river in the northeastern section of the study area, which was heavily frequented by gold miners and trespassing boats. These observations accord with the conclusions of Naing et al. [26], who drew attention to the greater abundance of felids in the less threatened zones of the park. Tigers are well known to adapt to human disturbance, where they are not directly persecuted [60-62]. Our field observations may suggest the active persecution of tigers, likely in the form of elevated poaching, in areas where human activity was highest. The lack of observed avoidance of these areas by the other felid species suggests they may be less vulnerable to human disturbance or poaching than tigers are.

Human disturbance, as detected on our cameras, was very frequent on the former logging roads connecting the western and eastern parts of the sanctuary, and all five species, most especially clouded leopards, were positively associated with these areas, and thus human detections, suggesting no avoidance of human activity, and active selection of roads and trails due to their facilitation of movement (e.g., [9]). Similarly, male Sunda clouded leopards have been found to preferentially travel roads and trails in Sabah, Borneo [9], and also in Kalimantan, Borneo [63]. However, this shared use of trails by humans and felids may come at the cost of increased poaching risk. Therefore, we suggest documenting old logging trails and keeping them under constant patrols, especially during mating seasons and dry seasons when these felids are most mobile and therefore most vulnerable.

\subsection{Scope and Limitations}

Camera trapping data provide powerful, but limited, insight into species niches. The locations and times at which the different species are detected across our large and long-term survey provide valuable insight into overlap in space and time of these species. However, the data are limited to detections at the location of the camera traps and thus do not reflect the full spatial and temporal activity pattern of any of the focal species. In addition, we designed our surveys targeting larger carnivores, which may affect comparisons of estimations among them. However, it is also not possible to simultaneously design a survey for all species, and we had to choose the largest extent for covariates in space use estimations. GPS telemetry on multiple individuals of each of the species in the same study region would provide a valuable comparison from a dataset that provides much higher precision of temporal and spatial activity and also provides measures of space-time avoidance of guild members that camera data cannot provide.

While camera trapping provides only snapshots, our study benefitted from the amalgamation of several datasets providing coverage across an unusually large extent in both space and time, which improves the clarity of our conclusions. We also faced the likelihood of low detection probabilities in the dense forest of HMS, the unknown proportion of arboreal activity amongst the species [22], and the equally unknown detail of their prey species (or age). We excluded some data while standardising the analysis of space use, but we maximised the inclusion of data for diel activity analysis, which enables us to check the representativeness of species' detection and activity. The almost identical activity pattern revealed that using two datasets with different sample sizes provided confidence in our 
interpretation of temporal and, albeit to a lesser extent, spatial overlap. Our survey also provided the comparable findings for temporal activity of felids in the region locally [64] and others (Table S7, Supplementary Material).

We focused on interactions among five co-occurring felid species given the expected strong interactions among them due to taxonomic and anatomical similarity. However, there are other species in this ecosystem that may affect the habitat use and temporal activity of these felid species through intimidation, kleptoparasitism, competitive exclusion, and mortality $[65,66]$. For example, the presence of dholes (Cuon alpinus) and Malayan sun bears (Helarctos malayanus) may affect all the studied species individually and interact to drive the process of mesopredator release in HWS. Dholes might be direct competitors for food with any of the felids [67], with observations suggesting this for at least the tiger and clouded leopard (e.g., [68]). By analogy, there are documented instances where a pack of dholes tree a leopard and even drive a tiger away from its kills [69,70]. In addition, dholes and bears, while not necessarily competing for food with Asiatic golden cats and marbled cats, might have antagonistic interactions that affect the space and temporal use of the smaller cat species. For example, leopards may kill sun bear cubs [71]. In a complex multi-species trophic community, mesopredator release might be affected by the presence of species dominant to them but subordinate to the apex species. Therefore, this study takes advantage of the strong morphological similarities between the five felids, simplifying the focus of competition between them while mindful of the wider network of interacting species and even more complex trophic interactions amongst the wider community of predators. Future work should face the considerable challenge of incorporating more carnivore species into such analyses of niche interaction and displacement.

The largest challenge our study faced in terms of providing a clear explanation of observed relationships is the fact that observational studies in single systems cannot reliably separate the multiple potential explanations of observed patterns (e.g., [55]). This is particularly the case in community ecology studies attempting to quantify the effects of competition on niche separation [72]. We found complex patterns of niche overlap and partial separation among five felid guild members that suggest varying degrees of niche differentiation; we cannot confirm the causes of these differences. We also acknowledge that the possibility of lower density of tigers and clouded leopards [26] than smaller felids in our study might induce uncertainty in the extent of our findings. For example, the tiger and clouded leopard may exist in depressed densities due to past poaching pressure, which might have relieved their competitive effects on other guild members. Experimental studies that either manipulatively [56] or mensuratively [57] control species co-occurrence patterns are needed to reliably infer the effects of current competition on niche structure and to separate it from evolutionary differences in adapted niche structure resulting, in part, from past competition in the evolutionary history of the species [72]. Thus, we strongly suggest future work with meta-replicated studies that provide multiple sampled landscapes with different species combinations, given the impossibility of manipulative species exclusion experiments for threatened and endangered species, such as felids in Southeast Asia.

\section{Conclusions}

Our study provided insights into the interaction of felid guild assemblage comprising different sized species in spatial and temporal dimension for the first time in the region surrounding Myanmar. Although spatio-temporal niche partitioning is technically challenging, we are able to apply the well-developed modelling approaches for single-species single-season occupancy and asymmetric multi-species interaction for space use and temporal activity overlaps. We found strong support for niche separation occurring mainly in the spatial niche dimension from our hypothesis tests, the largest displacement between the marbled cat and golden cat (but also substantial temporal displacement between tigerleopard cat and marbled cat-leopard cat). Tigers might be playing a dominant role in Htamanthi WS, while there is also a pattern of increasing displacement between species of similar sizes. However, our mesopredator release of golden cats and marbled cats 
resulting from the displacement of clouded leopards by tigers is poorly supported. We also noticed that the morphology and behaviour might be more important than size alone while studying anatomically similar species, in our case, arboreally active clouded leopard and marbled cats. We recognise that our analysis did not explicitly account for possible interactions with other carnivores and/or prey species, and we suggest future studies that allow us to understand multi-species interactions in both directions. We also observed the uncertainties in the complex patterns of multiple species interaction and uncertainty regarding their causes. However, our methods will also be useful in future research to evaluate the robustness of our current findings with replicated surveys in different areas or regions hosting similar guild assemblage and improve our understanding of felid guild assemblage in fundamental ecology.

Supplementary Materials: The following are available online at https:/ /www.mdpi.com/article/10 .3390/ijgi10120808/s1, Table S1: Survey information and camera trap locations used for space use analysis in Htamanthi Wildlife Sanctuary during 2014-2018, Method S1: Single-species occupancy modelling and covariate selection, Figure S1: Correlation test of covariates affecting occupancy of four cat species for single-species single-season occupancy modelling, Table S2: Beta parameter estimates for occupancy $(\mathbf{\Psi})$, detection probability $(\mathbf{P})$, and standard errors (SE) from model averaging results for each felid species, Table S3: Model selection for single-species occupancy modelling ranked by delta AICC $<2$ and QAIC $<2$, Table S4: Naïve occupancy, detection probability, and occupancy estimate of tiger, clouded leopard, golden cat, and marbled cat and beta estimates for effect of covariates from top models with standard errors under maximum likelihood framework selected based on AICc and QAIC, Table S5: Models with 300,000 iterations and 50,000 burn-ins with a thinning rate of five for two-species single-season occupancy modelling with effects of covariates to each species, Figure S2: Sensitivity testing of priors using different standard deviation (SD) values for two-species single-season occupancy modelling, Figure S3: Overlap in two species occupancy modelling with the $95 \%$ credible density interval of the mean of posterior distribution of parameter estimates, Table S6: Comparison of bootstrapped means for smoothing using different bandwidth values $(c=1, c=0.1$, and $c=0.5)$ to check the sensitivity of the smoothing effect derived for both sample sizes $(n=1344$ and $n=823$ ) for activity pattern overlap, Table S7: Observed temporal activity of tiger, clouded leopard, Asiatic golden cat, marbled cat, and leopard cat in Htamanthi Wildlife Sanctuary and comparison to findings around the Southeast Asia region, Figure S4: Diel activity of tiger, clouded leopard, Asiatic golden cat, marbled cat, and leopard cat, Figure S5: Activity overlap of tiger, clouded leopard, marbled cat, and Asiatic golden cat from occupancy survey data $(n=823)$, Table S8: Model metrices for Mantel test evaluating the support for each hypothesis, Table S9: Ranking support for joint niche separation hypotheses across spatial, temporal, and combined dimensions.

Author Contributions: Pyae Phyoe Kyaw, David W. Macdonald, Hla Naing and Saw Htun conceived and designed the project. Pyae Phyoe Kyaw and Hla Naing collected and compiled the data. Data analysis was done by Pyae Phyoe Kyaw, Ugyen Penjor and SC. Pyae Phyoe Kyaw, David W. Macdonald, Ugyen Penjor, Saw Htun, Hla Naing, Dawn Burnham, Żaneta Kaszta, and Samuel A. Cushman wrote the manuscript. All authors have read and agreed to the published version of the manuscript.

Funding: This research received no external funding.

Data Availability Statement: The data presented in this study are available on request from the corresponding author. The data are not publicly available due to the sensitive location of Endangered (tiger) and Vulnerable (clouded leopard) species. Additional supporting results are reported with the Supplemental Material.

Acknowledgments: WildCRU's fieldwork and the post-graduate scholarship held by PPK were funded by a grant to DWM from the Robertson Foundation. We thank the IUCN and German Development Bank, KFW and Instituto Oikos in partner with Foundation Segre for generous funding for the field surveys. We thank the Myanmar Forest Department; particularly Director General Nyi Nyi Kyaw for permission to conduct field surveys and Park Wardens of Htamanthi Wildlife Sanctuary, U Than Lin and U Win Hlaing for supporting the field surveys. We are grateful to Eric Ash, Luca Chiaverini, and Andrew Hearn for helpful comments on an earlier draft and to Mohammad Farhadinia, Egil Droge, Lara Sousa, and Iding Haidir for advice throughout. Finally, we thank our 
colleagues in Htamanthi Training and Research Centre for data compilation, and all members of the biological monitoring team, range officers, rangers, forest staff and forest guards, local community guards, and community guardians for their tireless efforts in the field.

Conflicts of Interest: The authors declare no conflict of interest.

\section{References}

1. Hutchinson, G.E. Concluding remarks. Population studies: Animal ecology and demography. Cold Spring Harb. Symp. Quant. Biol. 1957, 22, 415-427. [CrossRef]

2. Hegel, T.M.; Mysterud, A.; Huettmann, F.; Stenseth, N.C. Interacting effect of wolves and climate on recruitment in a northern mountain caribou population. Oikos 2010, 119, 1453-1461. [CrossRef]

3. Blonder, B. Hypervolume concepts in niche- and trait-based ecology. Ecography (Cop.) 2018, 41, 1441-1455. [CrossRef]

4. Mayor, S.J.; Schneider, D.C.; Schaefer, J.A.; Mahoney, S.P. Habitat selection at multiple scales. Ecoscience 2009, 16, 238-247. [CrossRef]

5. Hardin, G. The Competitive Exclusion Principle. Science 1960, 131, 1292-1297. [CrossRef] [PubMed]

6. Dayan, T.; Simberloff, D.; Yom-tov, Y. Inter- and intraspecific character displacement in mustelids. Ecol. Res. 1989, 70, 1526-1539. [CrossRef]

7. Macdonald, D.W.; Sillero-zubiri, C. The Biology and Conservation of Wild Canids; Oxford University Press: New York, NY, USA, 2004.

8. Macdonald, D.W.; Newman, C.; Harrington, L.A. Biology and Conservation of Musteloids; Oxford University Press: New York, NY, USA, 2017

9. Hearn, A.J.; Cushman, S.A.; Ross, J.; Goossens, B.; Hunter, L.T.B.; Macdonald, D.W. Spatio-temporal ecology of sympatric felids on Borneo. Evidence for resource partitioning? PLoS ONE 2018, 13, e0200828. [CrossRef]

10. Macdonald, D.W.; Loveridge, A.J.; Nowell, K. Dramatis personae: An introduction to the wild felids. In The Biodiversity and Conservation of Wild Felids; Macdonald, D.W., Loveridge, A.J., Eds.; Oxford University Press: New York, NY, USA, 2010; pp. 3-58.

11. Macdonald, D.W.; Loveridge, A.J. Biology and Conservation of Wild Felids; Oxford University Press: New York, NY, USA, 2010.

12. De Oliveira, T.G.; Tortato, M.A.; Silveira, L.; Kasper, B.C.; Mazim, F.D.; Lucherini, M.; Jacomo, A.T.; Soares, J.B.G.; Marques, R.V.; Sunquist, M. Ocelot ecology and its effect on the small-felid guild in the lowland neotropics. In Biology and Conservation of Wild Felids; MacDonald, D.W., Loveridge, A.J., Eds.; Oxford University Press: New York, NY, USA, 2010; pp. 559-580.

13. Crooks, K.; Soule, M. Mesopredator release and avifaunal extinctions in a fragmented system. Nature 1999, $400,563-566$. [CrossRef]

14. Myers, N.; Mittermeier, R.A.; Mittermeier, C.G.; da Fonseca, G.A.B.; Kent, J. Biodiversity hotspots for conservation priorities. Nature 2000, 403, 853-858. [CrossRef]

15. Kaszta, Ż.; Cushman, S.A.; Macdonald, D.W. Prioritizing habitat core areas and corridors for a large carnivore across its range. Anim. Conserv. 2020, in press. [CrossRef]

16. Estes, J.A. Predators and ecosystem management. Wildl. Soc. Bull. 1996, 24, 390-396.

17. Caro, T. Behavior and conservation: A bridge too far? Trends Ecol. Evol. 2007, 22, 394-400. [CrossRef]

18. Macdonald, D.W.; Bothwell, H.M.; Kaszta, Ż.; Ash, E.; Bolongon, G.; Burnham, D.; Can, Ö.E.; Campos-Arceiz, A.; Channa, P.; Clements, G.R.; et al. Multi-scale habitat modelling identifies spatial conservation priorities for mainland clouded leopards (Neofelis nebulosa). Divers. Distrib. 2019, 25, 1639-1654. [CrossRef]

19. Can, Ö.E.; Yadav, B.P.; Johnson, P.J.; Ross, J.; D'Cruze, N.; Macdonald, D.W. Factors affecting the occurrence and activity of clouded leopards, common leopards and leopard cats in the Himalayas. Biodivers. Conserv. 2020, 29, 839-851. [CrossRef]

20. Cheyne, S.M.; MacDonald, D.W. Wild felid diversity and activity patterns in Sabangau peat-swamp forest, Indonesian Borneo. Oryx 2011, 45, 119-124. [CrossRef]

21. Singh, P.; Macdonald, D.W. Populations and activity patterns of clouded leopards and marbled cats in Dampa Tiger Reserve, India. J. Mammal. 2017, 98, 1453-1462. [CrossRef]

22. Haidir, I.A.; Macdonald, D.W.; Linkie, M. Assessing the spatiotemporal interactions of mesopredators in Sumatra's tropical rainforest. PLOS ONE 2018, 13, e0202876. [CrossRef]

23. Haidir, I.A.; Dinata, Y.; Linkie, M.; Macdonald, D.W. Asiatic golden cat and Sunda clouded leopard occupancy in the Kerinci Seblat landscape, West-Central Sumatra. CatNews 2013, 59, 7-10.

24. Odden, M.; Wegge, P.; Fredriksen, T. Do tigers displace leopards? If so, why? Ecol. Res. 2010, 25, 875-881. [CrossRef]

25. Arino, O.; Ramos Perez, J.J.; Kalogirou, V.; Bontemps, S.; Defourny, P.; Van Bogaert, E. Global Land Cover Map for 2009 (GlobCover 2009). Available online: https:/ / doi.org/10.1594/PANGAEA.787668 (accessed on 5 January 2020).

26. Naing, H.; Ross, J.; Burnham, D.; Htun, S.; Macdonald, D.W. Population density estimates and conservation concern for clouded leopards Neofelis nebulosa, marbled cats Pardofelis marmorata and tigers Panthera tigris in Htamanthi Wildlife Sanctuary, Sagaing, Myanmar. Oryx 2019, 53, 654-662. [CrossRef]

27. Rabinowitz, A.; Schaller, G.B.; Uga, U. A survey to assess the status of Sumatran rhinoceros and other large mammal species in Tamanthi Wildlife Sanctuary, Myanmar. Oryx 1995, 29, 123-128. [CrossRef]

28. BRSoftware BR's EXIFextracter. Available online: https://www.br-software.com/extracter.html (accessed on 22 May 2019).

29. PantheraCameraTrap Camera Trap File Manager. Available online: http:/ / pantheracameratrap.org (accessed on 13 March 2018). 
30. Olliff, E.R.R.; Cline, C.W.; Bruen, D.C.; Yarmchuk, E.J.; Pickles, R.S.A.; Hunter, L. The Panthercam-a camera-trap optimized for monitoring wild felids. Wild Felid Monit. 2013, 7, 21-28.

31. Davey, K.; Wacher, T.; Amin, R. Analysis tool for camera trap survey data, ZSL. (In Prep). 2015.

32. MacKenzie, D.I.; Nichols, J.D.; Lachman, G.B.; Droege, S.; Royle, A.A.; Langtimm, C.A. Estimating site occupancy rates when detection probabilities are less than one. Ecology 2002, 83, 2248-2255. [CrossRef]

33. MacKenzie, D.I.; Nichols, J.D.; Royle, J.A.; Pollock, K.H.; Bailey, L.L.; Hines, J.E. Occupancy Estimation and Modeling: Inferring Patterns and Dynamics of Species Occurrence, 2nd ed.; Academic Press: London, UK, 2017.

34. Bischof, R.; Ali, H.; Kabir, M.; Hameed, S.; Nawaz, M.A. Being the underdog: An elusive small carnivore uses space with prey and time without enemies. J. Zool. 2014, 293, 40-48. [CrossRef]

35. Waddle, J.H.; Dorazio, R.M.; Walls, S.C.; Rice, K.G.; Schuman, M.J.; Mazzotti, F.J.; Waddle, J.H.; Dorazio, R.M.; Walls, S.C.; Rice, K.G.; et al. A new parameterization for estimating co-occurrence of interacting species. Ecol. Appl. 2010, 20, 1467-1475. [CrossRef]

36. Northrup, J.M.; Gerber, B.D. A comment on priors for Bayesian occupancy models. PLoS ONE 2018, 13, e0192819. [CrossRef]

37. Gelman, A.; Carlin, J.B.; Stern, H.S.; Dunson, D.B.; Vehtari, A.; Rubin, D.B. Bayesian Data Analysis, 3rd ed.; Chapman and Hall/CRC: London, UK, 2013.

38. Gelman, A.; Rubin, D.B. Inference from iterative simulation using multiple sequences. Stat. Sci. 1992, 7, 457-472. [CrossRef]

39. Su, Y.-S.; Yajima, M. Using R to Run “JAGS". Available online: https://cran.r-project.org/package=R2jags (accessed on 9 December 2020).

40. R Core Team R: A Language and Environment for Statistical Computing. Available online: http:/ / www.r-project.org/ (accessed on 12 September 2020).

41. Plummer, M. JAGS: A Program for Analysis of Bayesian Graphical Models Using Gibbs Sampling; 2003. Available online: https:/ / www.r-project.org/conferences/DSC-2003/Proceedings/Plummer.pdf (accessed on 12 November 2021).

42. Lynam, A.J.; Jenks, K.E.; Steinmetz, R.; Reed, D.H. Terrestrial activity patterns of wild cats from camera-trapping. Raffles Bull. Zool. 2013, 61, 407-415.

43. Linkie, M.; Ridout, M. Assessing tiger-prey interactions in Sumatran rainforests. J. Zool. 2011, 284, 224-229. [CrossRef]

44. Wand, M.P.; Jones, M.C. Kernal Smoothing, 1st ed.; Chapman and Hall/CRC: New York, NY, USA, $1994 ;$ ISBN 9780412552700.

45. Meredith, M.; Ridout, M.S. Overview of the Overlap Package. Available online: https://cran.r-project.org/web/packages/ overlap/vignettes/overlap.pdf (accessed on 9 December 2020).

46. Ridout, M.S.; Linkie, M. Estimating overlap of daily activity patterns from camera trap data. J. Agric. Biol. Environ. Stat. 2009, 14, 322-337. [CrossRef]

47. Mantel, N. The Detection of Disease Clustering and a Generalized Regression Approach. Cancer Res. 1967, 27, 209-220. [PubMed]

48. Legendre, P.; Legendre, L. Numerical Ecology; Elsevier: Amsterdam, The Netherlands, 1998.

49. Ash, E.; Cushman, S.A.; Macdonald, D.W.; Redford, T.; Kaszta, Ż. How important are resistance, dispersal ability, population density and mortality in temporally dynamic simulations of population connectivity? A case study of tigers in Southeast Asia. Land 2020, 9, 415. [CrossRef]

50. Cushman, S.A.; McKelvey, K.S.; Hayden, J.; Schwartz, M.K. Gene flow in complex landscapes: Testing multiple hypotheses with causal modeling. Am. Nat. 2006, 168, 486-499. [CrossRef] [PubMed]

51. Cushman, S.A.; Max, T.; Meneses, N.; Evans, L.M.; Ferrier, S.; Honchak, B.; Whitham, T.G.; Allan, G.J. Landscape genetic connectivity in a riparian foundation tree is jointly driven by climatic gradients and river networks. Ecol. Appl. 2014, 24, 1000-1014. [CrossRef]

52. Sunquist, M.; Sunquist, F. Marbled cat Pardofelis marmorata(Martin 1837). In Wild Cats of the World; The University of Chicago Press: Chicago, IL, USA, 2002; pp. 373-376. ISBN 978-0-226-77999-7.

53. Soule, M.E.; Bolger, D.T.; Alberts, A.C.; Wright, J.; Sorice, M.; Hill, S. Reconstructed dynamics of rapid extinctions of chaparralrequiring birds in urban habitat islands. Conserv. Biol. 1988, 2, 75-92. [CrossRef]

54. Sunarto, S.; Kelly, M.J.; Parakkasi, K.; Hutajulu, M.B. Cat coexistence in central Sumatra: Ecological characteristics, spatial and temporal overlap, and implications for management. J. Zool. 2015, 296, 104-115. [CrossRef]

55. McGarigal, K.; Cushman, S.A. Comparative evaluation of experimental approaches to the study of habitat fragmentation effects. Ecol. Appl. 2002, 12, 335-345. [CrossRef]

56. Krebs, C.J. The experimental paradigm and long-term population studies. Int. J. Avian Sci. 1991, 133, 3-8. [CrossRef]

57. Chiaverini, L.; Macdonald, D.W.; Hearn, A.J.; Cheyne, S.M.; Haidir, I.A.; Hunter, L.T.B.; Kaszta, Z.; Linkie, M.; Macdonald, E.A.; Ross, J.; et al. Hostility and tyranny in the uneasy coexistence in guilds of Sunda Islands felids, from tigers to leopard cats. Manuscript in preparation. 2020.

58. Rabinowitz, A.; Andau, P.; Chai, P.P.K. The clouded leopard in Malaysian Borneo. Oryx 1987, 21, 107-111. [CrossRef]

59. Hunter, L. Wild Cats of the World, 1st ed.; Bloomsbury: London, UK, 2015.

60. Carter, N.H.; Shrestha, B.K.; Karki, J.B.; Pradhan, N.M.B.; Liu, J. Coexistence between wildlife and humans at fine spatial scales. Proc. Natl. Acad. Sci. USA 2012, 109, 15360-15365. [CrossRef]

61. Carter, N.H.; Jasny, M.; Gurung, B.; Liu, J. Impacts of people and tigers on leopard spatiotemporal activity patterns in a global biodiversity hotspot. Glob. Ecol. Conserv. 2015, 3, 149-162. [CrossRef]

62. Naha, D.; Jhala, Y.V.; Qureshi, Q.; Roy, M.; Sankar, K.; Gopal, R. Ranging, activity and habitat use by tigers in the mangrove forests of the Sundarban. PLoS ONE 2016, 11, e0152119. [CrossRef] 
63. Gordon, C.H.; Stewart, A.E. The use of logging roads by clouded leopard. Cat News 2007, 47, 12-13.

64. Zaw, T.; Myint, T.; Htun, S.; Po, S.H.T.; Latt, K.T.; Maung, M.; Lynam, A.J. Status and distribution of smaller cats in Myanmar. Cat News 2014, 8, 24-30.

65. Palomares, F.; Caro, T.M. Interspecific killing among mammalian carnivores. Am. Nat. 1999, 153, 492-508. [CrossRef]

66. Vanak, A.T.; Fortin, D.; Thaker, M.; Ogden, M.; Owen, C.; Greatwood, S.; Slotow, R. Moving to stay in place: Behavioral mechanisms for coexistence of African large carnivores. Ecology 2013, 94, 2619-2631. [CrossRef]

67. Thinley, P.; Kamler, J.; Wang, S.W.; Lham, K.; Stenkewitz, U.; Macdonald, D.W. Seasonal diet of dholes (Cuon alpinus) in northwestern Bhutan. Mamm. Biol. 2011, 76, 518-520. [CrossRef]

68. Singh, P.; Srivathsa, A.; MacDonald, D.W. Conservation status of the dhole Cuon alpinus in north-east India, with a focus on Dampa Tiger Reserve, Mizoram. Oryx 2019, 54, 873-877. [CrossRef]

69. Karanth, K.U.; Sunquist, M.E. Behavioural correlates of predation by tiger (Panthera tigris), leopard (Panthera pardus) and dhole (Cuon alpinus) in Nagarahole, India. J. Zool. 2000, 250, 255-265. [CrossRef]

70. Venkataraman, A.B. Do dholes (Cuon alpinus) live in packs in response to competition with or predation by large cats? Curr. Sci. 1995, 69, 934-936.

71. Naing, H.; Htun, S.; Kamler, J.F.; Burnham, D.; Macdonald, D.W. Large carnivores as potential predators of sun bears. Ursus 2019, 30, 51-57. [CrossRef]

72. Connell, J.H. Diversity and the coevolution of competitors, or the ghost of competition past. Oikos 1980, 35, 131-138. [CrossRef] 